\title{
Introduction: learning from teaching failures, achieving teaching successes Sabine Baumann
}

To have failed is to have striven, to have striven is to have grown.

(Maltbie Davenport Babcock)

Failure is disguised success.

(Matshona Dhliwayo)

Teaching is personal. Teaching is challenging. Teaching is diverse. Teaching can be messy. Teaching - even the same module - is always different. Teaching is about people.

The idea for Teaching Strategic Management: A Hands-on Guide to Teaching came from a curiosity about why we as faculty and instructors rarely share our personal stories of failure in the classroom, but instead place so much emphasis on celebrating streamlined and frequently impracticable "best" practices. We all know these moments when well-planned teaching concepts fall apart in the classroom, when students become disengaged or when we realize during grading that the flaw was in the concept or our teaching rather than students' being unprepared for the assessment. However, experienced faculty also know that what may have started out as a failure often turns out to be the root of wonderful teaching successes. Therefore it is so important to share what it takes to turn failures in the classroom into those marvelous moments when our hard work and meticulous preparation culminate in students' finally mastering difficult concepts and when a sense of enlightenment and deep satisfaction fills the classroom.

Teaching is diverse. Teaching is truly challenging. There is an extensive array of diverse challenges ranging from dealing with heterogeneous student groups to teaching specific methods such as design thinking, grading, teaching strategic management to particular student groups such as nonbusiness students or executives, how to bring practice into the classroom, teaching online, and so on. Especially junior faculty find the first steps as a teacher a tough contest. Nevertheless, experienced faculty know that you 
never stop growing as a teacher and that the next challenge is just around the corner. Regardless of their experience, what they all need are teaching resources with true applicability: What works and what doesn't work, and why?; How to ...?; and lessons learned and feasible practices. In other words: hands-on advice!

Teaching is personal. Teaching is about people. Therefore this guide for teaching strategic management grounds in a deeply personal approach and provides a teaching resource with a high degree of applicability for the classroom. In all chapters, experienced contributors share individual accounts of classroom experiences and offer insightful advice on how to address the teaching strategic management challenge they cover in their chapter. Each chapter also provides specific examples such as syllabi, teaching plans, reading lists, case studies, assignments, and exercises that can be directly used in teaching. We wanted to not only make this an interesting read, but to also make this volume truly relevant for teachers of strategic management.

The first part of this volume covers "Teaching Strategic Management History and Newly Evolving Fields." In her chapter on "Teaching the History of Strategic Management" Päivi Maijanen provides a historical perspective to strategic management and its core question of why some firms outperform others. This question is used to elucidate the evolution of strategic management as a field where theory and practice are tightly connected. Consequently, teaching about the history of strategic management combines teaching changes in the business environment and the related theoretical developments. Maijanen presents course material covering the core theories and concepts of strategic management and suggestions for course assignments.

Chapter 2 covers "Teaching Strategy as an Ethical Practice." Sven-Ove Horst describes strategy as a reflective practice that entails ethical responsibilities and explains how strategy can be taught with a strong ethical sensibility. After reviewing some relevant discussions around strategy teaching, Horst develops a frame for seeing the ethical side of strategy as part of a strategy-as-practice approach. He connects this frame with his experience of teaching a course on strategic management at the University of Navarra in Spain to discuss value-based strategy teaching in this context. He shows how the university's core values provide the basis for learning how to act with care and responsibility as a strategist. Provided course assignments demonstrate potential student learning outcomes.

In the third chapter "Teaching Sustainability in Strategic Management," Britta Boyd addresses sustainability as an increasingly prominent part of corporate social responsibility within strategic management. The objective is to provide students with an understanding and comprehensive knowl- 
edge of the development of sustainability, legal responsibilities of different actors and corporate social responsibility (CSR) activities in strategic management. The chapter attaches special importance to the conceptual evolutionary path of theories and practices in sustainability development and provides assignments for student reflection on its implications.

Part II of this volume covers "Methods for Teaching Strategic Management." Candace M. TenBrink and Krysti Turnquest in their chapter on "Service Learning in Strategic Management: Opportunities, Challenges, and Examples" explain how the experiential teaching method of service learning can help students of strategy overcome a lack of strategy knowledge and experience and help them grasp the breadth and depth of strategy. After a brief description of the history of service learning the authors discuss why this pedagogy may be a positive learning tool in strategic management and offer benefits and obstacles in deploying it. The chapter provides several cases to assist with planning a service learning course and questions to invoke an insightful discussion.

In a similar vein, Richard R. Smith and Patrick Tan in Chapter 5 further explore the "Experiential Approach to Strategy Formulation." They argue that the methods for teaching strategy formulation are often left to conceptual frameworks and generic toolsets in the business school classroom while, ultimately, strategy formulation is about taking action. Therefore, one of the best ways to teach it is through physical application via the experiential approach. Their chapter introduces the background associated with teaching strategy and experiential approaches, provides an overview of the concepts used to making teaching in an experiential format most effective, demonstrates a proven process for teaching in this method, and considers several discussion questions. The authors share their experiences, challenges and insights as they experimented with and taught business practicum courses.

In Chapter 6, Uwe Stratmann shows how "Writing and Using Your Own Case Study for Strategy Teaching" is a very effective instrument to combine theory with practice and to involve students in a very active way. Different to the use of existing, secondary teaching cases, his chapter focuses on the production and use of a teacher's own case study. Writing and integrating one's own teaching case is very beneficial in terms of the alignment between teaching content and the case as well as the overall involvement of both sides, the lecturer and the students. The chapter describes an effective case study writing process as well as methods to integrate the case into the teaching concept. The writing process and didactical methods are exemplified by a case study on Nespresso, in order to provide pragmatic advice and to show outcomes in terms of learning and teaching success.

Sabine Reisinger in Chapter 7 evaluates "Interactive Exercises, Peer 
Coaching, and Videos in Strategic Management Education" to help students develop the strategic competences needed to run a business in today's digitized, highly connected, globalized world. By integrating interactive methods into strategic management courses, students of Generation $\mathrm{Y}$ and $\mathrm{Z}$ can build conceptual and analytical knowledge as well as develop strategic, personal and interpersonal competencies. Her toolbox for strategic management courses provides interactive methods to discuss different beliefs, views and perspectives and to facilitate the understanding of complex topics and theories. Most of the described methods can be used in class and/or online. Two comprehensive teaching designs show in detail how interactive methods can be integrated into a strategic management course. The first is suitable for teaching complex theories and concepts of strategy and/or new subjects like platform industries, value networks or business ecosystems. The second enables students to develop an understanding of the complexity of strategy by applying strategy tools in peer groups.

In Chapter 8, Norman T. Sheehan introduces "Tailored Methods of Strategizing in Undergraduate Education: From SWOT to the 6Ps of Business Strategy." His experience is that while students are typically able to leverage their SWOT analysis to formulate potentially profitable strategies, their proposed strategies are often incomplete or the elements of strategy are not aligned with each other. His chapter provides a strategy formulation tool, the 6Ps of Business Strategy, which instructors can use to help students formulate business strategies that are comprehensive and coherent as well as profitable. The framework can also be used to compare and contrast business strategies as well as diagnose why some strategies have failed. The 6Ps reinforce that effective strategies fully integrate all functional areas and they have been successfully applied by undergraduate and masters' students, managers and company directors.

Chapter 9, "Teaching Strategy by Not Teaching Strategy," completes the second part on methods. Robert P. Wright shares his discovery that when teachers teach less, students end up learning more. The author demonstrates the benefits of going back to the basics of children's learning - enthusiastically and with a lot of fun. He outlines his strategies for better preparing, cultivating and nurturing the next generation of thought-leaders in the teaching of strategic management. In this process of continuous renewal he presents a pedagogical innovation - the FOCUSED framework - that has enriched and enabled students to learn beyond the domain of strategy, strategizing and strategic management. What started off as a simple fun teaching tool is now being used by senior executives to help them better deal with their unsolved problems, issues and challenges.

Part III of this volume addresses "Teaching Strategic Management for 
Particular Groups of Learners and Teaching Settings.” David R. King and Aiden E. Sizemore, Chapter 10, start off with "Strategic Management in Online and Hybrid Courses." They explain that after developing techniques to teach in traditional classrooms, a move to teach online can be daunting. In their chapter, the authors provide the background on online classes and important considerations specific to online instruction. They discuss common challenges and their solutions prior to specific sections that outline how to develop a syllabus, grade online, adapt exercises and case assignments online for different size course enrollments, and how to design and manage discussion boards. They also identify tools and resources available for making the transition to online teaching easier.

In Chapter 11, Geoffrey Graybeal provides insights on "Teaching Strategic Management for Media Students." Being an educator who has taught both majors, he discusses differences between teaching business students and teaching media students. His chapter outlines three primary challenges and solutions to teaching strategic management to media students. It explores syllabus development for strategic management courses for media students and presents a list of suggested textbooks and resources for developing courses while providing an overview of some of the top scholarly journals and organizations dedicated to the academic subdiscipline of media management, economics and entrepreneurship. Methods of delivery for course material and themes for course discussion questions are also offered in the chapter, as are sample assignments that could be incorporated or adapted into undergraduate or graduate level courses on strategic management for media students.

"Teaching Strategy Work to Business Students" is explored by Rita Järventie-Thesleff and Janne Tienari in Chapter 12. They start out with a brief introduction to the "relevance debate," whether business schools offer students the knowledge and skills needed for success in an increasingly complex and volatile world including the necessary ethical grounding of their business education. Moreover, the uncertainties of the operating environment set new requirements for teaching strategic management - or strategy work, as the authors prefer to call it - to digital-native business students. In their chapter, they argue for an approach based on strategyas-practice as an alternative to teaching traditional positivistic techniques of strategic inquiry. The authors offer concrete suggestions regarding teaching methods and learning outcomes based on their teaching experiences. They propose inclusion of a set of themes in course curricula and discuss pedagogical methods that will facilitate a synthesis of research and business practice.

Dianne Tyers and John Bourke complete Part III and also this volume with their contribution on "Teaching Strategic Management for 
Executives." Chapter 13 discusses the unique characteristics executives have as learners that need to be addressed when considering how best to enable them to learn about strategic management. The authors outline the challenges educators face and how to overcome them, covering everything from course design to delivery. Central to their approach is the content that goes into the course syllabus and the approach to delivering it. The authors hold that educators need to achieve more than merely succeed in having executives learn about strategic management - they need to be able to apply their learning. This requires executives to learn how to manage strategically, something that starts with understanding strategy, and how to craft and implement it, and continues with embracing leadership for organizational adaptability. The authors explore a repertoire of approaches from which teachers of strategic management can select to meet the needs of executive learners.

Teaching Strategic Management: A Hands-on Guide to Teaching Success aims to provide instructors, faculty, and program directors of strategic management courses at undergraduate, graduate, and executive levels with an enlightening and instructive guide for teaching and for creating course syllabi and teaching plans. The editor of this volume and the contributors hope that the wealth of material provided in this guide benefits faculty and instructors of strategic management, be they experienced and seeking inspiration for new methods, or needing guidance for developing a new course. We hope this guide sparks an ongoing sharing of teaching experiences and advice, and paves the way to those "marvelous moments" when the classroom is full of inspiration, insight, and fun. 